\title{
Batman y el Joker: a la luz de Derrida y Bajtín
}

\section{Batman and the Joker analyzed following Derrida and Bajtín}

\author{
José Marco Segura Jaubert \\ Escuela Ecuménica de Ciencias de la Religión \\ Universidad Nacional, Costa Rica \\ jose.segura.jaubert@una.cr
}

\begin{abstract}
Resumen
Se aplica el acercamiento textual derridiano al género del cómic junto al lenguaje fílmico. Con el fin de realizar el análisis se toman los cómics The Killing Joke de Alan Moore (1988) y Arkham Asylum: A serious house on a serious Earth de Grant Morrison (1989), y dentro del género fílmico The Dark Knight (2009), dirigida por el cineasta Christopher Nolan. Posteriormente se agrega una lectura complementaria desde la visión de Bajtín (2003), a partir de la cual se puede extrapolar la noción del Joker como heredero de la tradición rabelesca, que François Rabelais ya había desarrollado en sus clásicos Gargantúa (1534) y Pantagruel (1532).
\end{abstract}

Palabras claves: deconstrucción, Historia de la Risa, héroe, villano, cómic, cine

\begin{abstract}
The author applies Derrida's textual approach to the comic gender in connection to film language. To do the analysis are taken into account the comics The Killing Joke (Allan Moore, 1988), and Arkham Asylum: A serious house on a serious Earth (Grant Morrison, 1989), as well as the movie The Dark Knight (Christopher Nolan, 2009). A complementary reading from the vision of Bajtín (2003) lets extrapolate the notion of Joker as heir of the Rabelesque tradition, developed by François Rabelais in his classic stories Gargantua (1534) and Pantagruel (1532).
\end{abstract}

Keywords: deconstruction, History of the Laugh, hero, villian, comic, film 


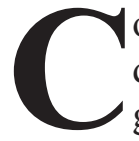

omo es conocido, el pensamiento derridiano trata de desmontar la lógica binaria que ha regido la metafísica de Occidente desde que se recuerda. Esto lo logra mediante la historización de los conceptos, que son ubicados de acuerdo con sus coordenadas en el tiempo y en el espacio. De este modo, se permite leer lo que ha significado cada uno de estos conceptos en un momento determinado de la historia. Partiendo de ahí, se realiza la inclusión de los pares binarios que, al "resquebrajarse" (en el sentido de que al confrontarse los conceptos opuestos aparecen tendencias y predominios), proporcionan nuevas "nociones de verdad", lo cual es la finalidad de Derrida (2008) en sus estudios.

El concepto que se historiza en este artículo es el de héroe que plantea Bauzá (1998):

Si tuviéramos que escoger una nota distintiva con que caracterizarlos - una suerte de común denominador - diríamos que el aspecto más destacable y por el que el imaginario popular los ha entronizado como héroes, es el móvil ético de su acción orientada siempre a conseguir un mundo mejor, tal como hemos apuntado. (p.7)

Como se observa, no importa en qué época se ubique al héroe; este, mediante una forma ética de vida, que va de acuerdo con los principios y valores de la sociedad imperante, busca el bien para la comunidad a la que pertenece, por ejemplo Eneas en Roma o Superman en Metrópolis. Podría decirse que la noción de héroe dada por Bauzá (1998) es general y no historizada, por lo que se puede dudar de ella. Para ahondar sobre este aspecto, se realiza una descripción de los pares binarios, que ayudará a descentralizar y a dar una nueva perspectiva del Joker y de Batman, personajes centrales de los cómics y del filme.

Se utilizan los siguientes pares binarios: Héroe / Villano, Bien / Mal, Razón / Locura.

\section{Par binario: Héroe / Villano}

Se inicia este par binario con la discusión que mantienen Rachel Dawes y el Mayordomo Alfred en The Dark Knight (2009):

Alfred: Quizás tanto Bruce como el Señor Dent creen que Batman representa algo más importante que las demandas de un terrorista, Señorita Dawes, incluso si todos llegan a odiarlo por eso. Ese es el sacrificio que él está haciendo... No para ser un héroe. Sino para ser algo más.

Rachel: Bueno, tienes razón en cuanto a una cosa, dejar que Harvey tome su lugar, no es para nada heroico. (Nolan, 2009)

Esta cita deja en claro que Batman no se mantiene dentro del camino ético de un héroe; recurre a otros medios para lograr sus fines y deja que un civil cualquiera tome su puesto ante la sociedad, el cual no tiene ni sus habilidades mentales ni su poder físico para enfrentarse a un villano como el Joker.

Esta noción se enfatiza más dentro del filme en la escena de la comisaría entre Batman y el Joker:

Batman: ¿Entonces por qué quieres matarme?

Joker: JAJAJA. . ¿ ¿Matarte? Yo no quiero matarte. ¿Qué haría sin ti? ¿Volverle a robar a los narcotraficantes? No...Tú... Tú me complementas. (Nolan 2009) 
En estas líneas se sintetiza lo que sucede en los cómics y en la película que se analizan. El mensaje es claro: toda persona es tan buena como el mundo en que vive se lo permita, en el momento en que no necesita a la figura heroica la considera un estorbo y la desecha. De acuerdo con esta lectura, tanto la moral como el resto de los valores están sujetos a lo que la sociedad defina.

Dentro de la lectura que propone Derrida, el héroe como tal no existe $y$, por antonomasia, el villano tampoco: el Joker se libera de esa etiqueta y deja de ser, por consecuencia, el loco de los textos. Se debe entonces repensar la figura de Batman, que siempre se ha identificado como el bueno o el cuerdo de la historia.

Batman en los cómics en estudio, y de manera más marcada en la película, se convierte en una moneda de sacrificio por el bien de la ciudad, un paria, alguien que ha transgredido la línea ética que plantea Bauzá (1998); es aquel que puede tomar el camino que sea, ético o no, para el bien de la ciudad.

El rol como héroe de la sociedad no existe dentro de la película, ni dentro de estos dos cómics que han servido de influencia para esta. Batman es un personaje que cree hacer lo correcto dentro de sus propias circunstancias de vida, que busca realizar acciones para dar con su objetivo; sin embargo, nunca delimita ni reflexiona sobre su manera de actuar, su fin justifica sus medios, no se pone en el lugar del otro. Por ende, al no existir un héroe no existe un villano, un par de etiquetas que no deberían portar ni Batman ni el Joker.

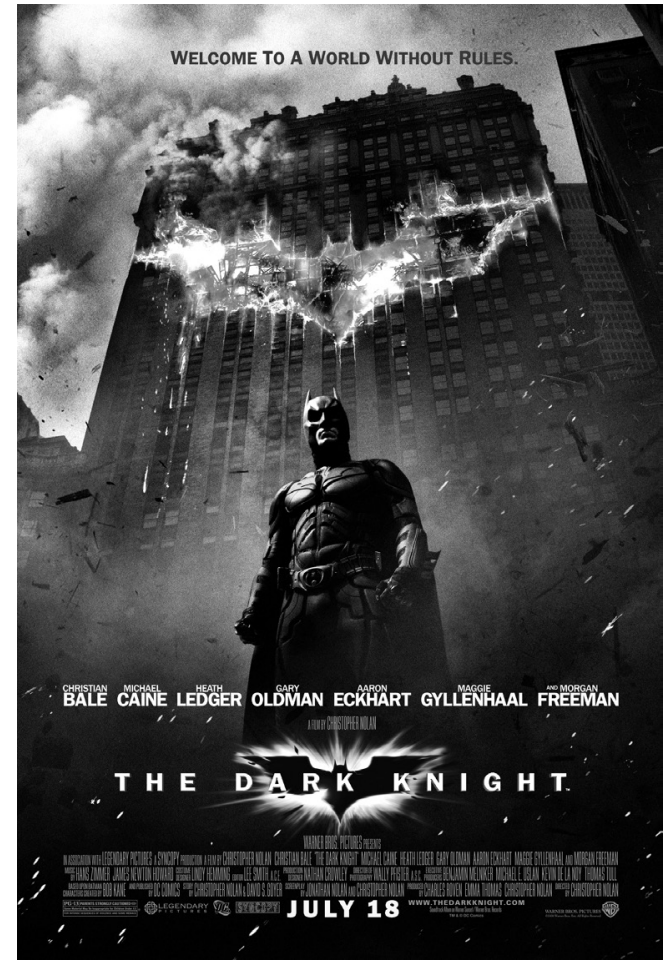

Imagen 1. Batman: The Dark Knight

Fuente: https://www.google.com/search?q=the+d ark+knight\&tbm=isch\&sxsrf=ACYBGNSf4rEVY uL-Nu6WQvDq8N9TphfqLw:1569177580620\&so urce $=$ lnt \&tbs $=$ isz: $1 \&$ sa $=X \&$ ved $=0$ ahUKEwiz46CC iuXkAhVnuVkKHTxFApIQpwUIIQ\&biw=1366\& bih=654\&dpr=1\#imgrc=FBxAVdhizdFA-M:

\section{Par binario: Razón/ Locura:}

Según la lógica derridiana, en este segundo par binario se observa cómo el Joker y Batman, considerados desde siempre loco y cuerdo respectivamente, se salen de estos márgenes.

En The Killing Joke (1988), se podría decir que las etiquetas de loco y de cuerdo son superadas, en el momento en que el Joker le cuenta una broma al hombre murciélago y este último, en lugar de buscar aniquilarlo, le sonríe. Esta acción 
da a entender que ambos personajes pertenecen a la misma esfera, que son las dos caras de una misma moneda, que están en una relación sin fin, donde ambos parecen antagonistas pero que en el fondo se comprenden. Incluso, Batman llega a tener compasión por su archirrival y llega a decir que él quizá sea el único que sabe cómo ayudarlo, ya que ha estado o está en el mismo lugar que él, dando a entender que su cordura no es tal. En otras palabras, la confrontación de los extremos llevaría a que los absolutos no existen, solo una infinita gama de estadios intermedios:

Batman: Si no tomas esta chance, en-
tonces estamos atrapados en un círculo
suicida. Nosotros dos, hasta la muerte.
No tiene por qué terminar así, no sé qué
fue lo que te hizo así, pero ¿quién lo
sabe? Talvez yo también he estado ahí.
(Moore, 1988)

En ambos textos, Batman se sale de la racionalidad, de la cordura que siempre se le ha adjudicado; en el Arkham Asylum (1989), llega al punto de darse cuenta de que él necesita a los villanos fuera del manicomio para atraparlos, y así justificarse consigo mismo y con la sociedad:

Batman: Soy yo. Soy yo quien tiene miedo. Tengo miedo de que el Joker pueda tener razón acerca de mí. A veces... cuestiono la racionalidad de mis acciones. Y temo que cuando camine por las puertas del Asilo de Arkham y las puertas se cierren detrás de mí... Sea simplemente como un regreso a casa. (Morrison, 1989)

Este segundo par binario se vuelve explícito en el filme dirigido por Christopher Nolan en sus escenas finales, cuando
Batman salva al Joker de morir y este último le expresa:

Joker: -Simplemente no pudiste dejarme ir, ¿verdad? Supongo que esto es lo que sucede cuando una fuerza imparable se topa con un objeto inamovible. Tú eres realmente incorruptible, ¿correcto? Tú no me matas por algún sentido moral fuera de lugar y yo no te mato porque eres demasiado divertido. Estamos destinados a hacer esto por siempre. (Nolan, 2009)

Igualmente, en esta película, al Joker le eliminan su etiqueta de loco y se propone una nueva noción de quién es, como se observa en la escena de la comisaría cuando el Joker le comenta al hombre murciélago "Ves, yo no soy un monstruo, simplemente estoy más adelantado" (Nolan, 2009).

De manera semejante, se modifica la percepción del Joker como loco en el Arkham Asylum (1989), cuando la psiquiatra que dirige el asilo responde a la pregunta de Batman acerca de la supuesta enfermedad que aqueja al Joker:

La Psiquiatra: El Joker es un caso especial. Algunos de nosotros sentimos que él está más allá del tratamiento. Incluso, ni siquiera estamos seguros sí podemos propiamente definirlo como demente.

(...)

Hemos empezado a pensar que podría ser un desorden neurológico, similar al síndrome de Tourette.

Es muy posible que estemos en presencia de algún tipo de super sanidad. Una brillante nueva modificación de la percepción humana. Más adaptada a la vida urbana de los fines del Siglo XX. (Morrison, 1989) 
La interpretación dual de loco y cuerdo ha sido invertida: el Joker, por una parte, se sale del juego de la locura para situarse un escalón más arriba y aunque en algunas ocasiones sabe que puede terminar en un asilo para locos, entiende que es parte de su naturaleza dual. Batman, por otra parte, ha dejado de ser aquel hombre racional que siempre está apegado a la razón, e incursiona en los dominios de su archirrival.

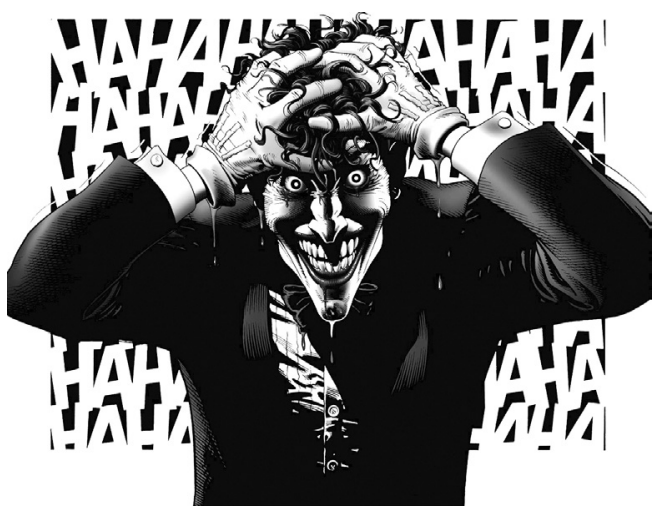

Imagen 2. Batman: The Killing Joke

Fuente: https://www.google.com/search?biw= $1366 \&$ bih $=654 \& \mathrm{tbs}=\mathrm{isz} \% 3 \mathrm{Al} \& \mathrm{tbm}=\mathrm{isch} \& \mathrm{~s}$ $\mathrm{xsrf}=\mathrm{ACY}$ B GNQ3 y-N6MCsK 9C 5 mec vhouz T5I_aUA\%3A1569177595888\&sa=1\&ei=-7HXe73NYOD5wK08ZHICQ\&q=the+killing+ joke\&oq $=$ the $+\&$ gs_l=img.3.1.35i3912j0i6718. 4208883.5637101..5638388_..1.0..3.157.1273. $0 \mathrm{j} 9 \ldots . . .0 \ldots . . .1 .$. gws-wiz-img.....10..0j35i362i39. KpfukA5W0Gg\#imgrc=K-P58_U8o2uFRM:

\section{Tercer par binario: Bien / Mal}

Con este tercer par binario los escritores introducen a un Batman que aparentemente transgrede la línea que distingue al héroe del villano y busca atrapar a su archirrival sin importar la forma de hacerlo.

En The Killing Joke (1988) se observa a Batman preocupado por la relación que sostiene con el príncipe del crimen, que al final puede llevar a uno de ellos o a ambos a la muerte. El hombre murciélago por regla no mata, mas coquetea con la idea:

Batman: ... últimamente he estado pensando en ti y en mí, en lo que nos va a pasar al final. Vamos a terminar matándonos, ¿Verdad? Talvez me mates tú, talvez te mate yo... (Moore, 1988)

Los escritores aprovechan la ambivalencia del arquetipo del Joker para añadir más complejidad al discurso, en el sentido de que el personaje como tal no tiene reglas, $\mathrm{y}$ al no tener reglas tiene mil caras, como se desprende del filme cuando Maroni -jefe de la mafia- habla con Batman:

Maroni: Nadie te dirá nada, ellos saben cómo actúas... tienes reglas. El Joker no tiene reglas. Nadie lo traicionaría por ti. Quieres a este tipo, tienes una forma. Y ya sabes cuál es. Solamente quítate la máscara y deja que él te encuentre. ¿O vas a dejar que unas personas más mueran mientras lo piensas? (Nolan, 2009)

Esta frase no solo destaca porque revela hasta qué punto ha llegado Batman para dar con su némesis, sino por el contexto en que es expresada: el justiciero de Ciudad Gótica lanza a Maroni, sin intención de darle muerte, desde un segundo piso para obtener la información necesaria.

Otra dimensión que surge dentro de la dicotomía Bien y Mal se muestra con claridad al final de The Dark Knight (2009), cuando Batman, personaje considerado moral y ético y que en teoría busca cumplir la ley, la transgrede al intentar atrapar al Joker. Esto queda en evidencia cuando Lucius Fox, ayudante de Empresas Wayne, 
habla con el caballero oscuro al darse cuenta de lo que su jefe ha realizado para dar con el paradero de su archienemigo:

Batman: Hermoso, ¿no crees?

Fox: Hermoso. Poco ético. Peligroso. Has vuelto cada teléfono de la ciudad en un micrófono...

Batman: ... En un generador / receptor de alta frecuencia.

Fox: Como el teléfono que le di en Hong Kong. Tomó el concepto que le di del sonar y lo aplicó a los teléfonos de todos en la ciudad. Con la mitad de la ciudad alimentando el sonar puede ver toda la ciudad. Esto está mal.

Batman: Tengo que encontrar a este hombre, Lucius.

Fox: ¿Pero a qué costo?

Batman: La base de datos está protegida. Solo puede ser accesada por una persona.

Fox: Nadie debería tener este tipo de poder.

Batman: Por eso te lo doy a ti. Solo tú puedes usarlo. (Nolan, 2009)

Para Batman, se aplica la máxima de que el fin justifica los medios, desea a toda costa frenar a su enemigo, sin importar qué tenga que sortear en el camino: maleantes, amigos o la ética.

Dentro de estas dicotomías, los autores admiten la necesidad del surgimiento del azar como nueva fuerza de equilibrio, pues los extremos terminan siendo equivalentes, necesitándose siempre el uno al otro, dando pie a una lectura gris, intermedia entre el negro y el blanco. Esto se nota cuando Batman, el Comisionado Gordon y Harvey Dent discuten durante la película:
Dent: He hecho suficiente mal.

Gordon. Solo que no lo suficiente. Aún.

Batman: No quieres herir al niño, Harvey.

Dent: No se trata de lo que yo quiera. Es acerca de lo que es justo. Creí que nosotros podíamos ser hombres decentes en tiempos indecentes, que podíamos guiar con el ejemplo. Creímos que podíamos manipular las reglas pero no romperlas... Estábamos equivocados. El mundo es cruel. La única moralidad en un mundo cruel es el azar. Imparcial. Sin precedentes. Justo. (Nolan, 2009)

En resumen, desde la lectura derridiana surge una nueva noción de verdad, los pares binarios se rompen, ya nada es como se conocía. Se está, aparentemente, ante un nuevo paradigma: "el azar" y el caos (entendido como la fuerza que rige el todo u orden superior) gobiernan. Las cosas se ven de manera diferente. Las fracturas que plantean los textos dejan atrás el viejo orden para enfatizar uno nuevo: los textos se revitalizan.

A partir de la lectura de Derrida, tanto en los textos literarios como en el discurso fílmico, el héroe, el villano, la Razón, la Locura, el Bien y el Mal, se resquebrajan. Se puede decir adiós a la lógica que siempre se ha planteado Occidente.

Se puede hacer una lectura complementaria sobre el Joker a partir de la visión de Mijail Bajtín, tema que se pasa a exponer.

\section{El Joker y la historia de la risa}

Bajtín (2003) primeramente analiza lo que es la risa durante la Edad Media y el Renacimiento, y señala que esta no se reduce a una simple y pura ridiculización, ya que 
conserva su integridad, su relación con la totalidad de la evolución vital, su bipolaridad y las tonalidades triunfantes del nacimiento y la renovación. La risa como tal conserva un profundo valor de la concepción del mundo, es una de las formas fundamentales a través de las cuales se expresa la humanidad y su historia. Es un punto de vista particular y universal sobre el orbe, que lo percibe en forma diferente, pero no menos importante que el punto de vista de lo serio: solo la risa puede capturar ciertos aspectos excepcionales del mundo.

Para Bajtín (2003), el discurso de Rabelais subvierte lo oficial, la buena vida que se sigue, el consumismo y el mercantilismo superfluo. La concepción de Bajtin (2003) aparece en The Killing Joke (1988) puesta en boca del Joker, quien expresa la necesidad de reír ante las desgracias de la vida humana:

Cuando la vida le parezca complicada, recuerde siempre esta tonada... Sólo hay una cosa cabal, que ahora le contaré tal cual y que me hace siempre sonreír... Me vuelvo loo-oo-ooco, como la luz a la polilla, me vuelvo loo-oo-ooco y hasta me como la alfombrilla... La vida es descansada en una celda acolchada, cantando de alegría... Allí cambian tu tristeza con presteza, gracias a dos inyecciones al día... Vuélvete loo-oo-ooco, víctima de un predicador o de las drogas poco a poo-oo-ooco $i Y$ cuando la raza humana vea las bombas caer y a tus hijos perecer no te preocuparás y sonre-ii-raas... Cuando estás loo-oo-ooco... Ves ante ti, luminoso, el universo grandioso... Si te hacen daño no seas huraño... Si tan mal la vida te parece... No te rebeles... ¡Enloqueeee-eecee! (Moore, 1988, pp. 25-26)
Aquí se observa la unión de la risa y de lo serio, aquella carcajada que la Iglesia católica no soportaba durante esas épocas, la que incluso llegó a ser excluida para reservarla a solo ciertos días. Como dice Bajtín (2003), la risa vivió y evolucionó fuera de la esfera oficial de la ideología y la literatura seria. Fue gracias a esta existencia no oficial que la cultura de la risa se distinguió, gracias también a su radicalismo, su libertad excepcional y su despiadada lucidez. Al vedar a la risa de licencia y del acceso a los medios oficiales de la vida y al volverse impune, se plantó fuera de estos límites: en la plaza pública, en las fiestas y en la literatura recreativa.

El personaje del Joker no es tomado en serio en la época actual. Aparece en el género del cómic, que no se toma como algo serio y es visto como literatura para niños, lo que permite señalar que aún en la actualidad la influencia de la Edad Media y el Renacimiento persiste. El cómic no es un texto para considerar, le sucede lo mismo que a la risa en siglos anteriores. El Joker es presentado por medio del cómic, del dibujo animado y de las películas que entretienen a una masa, no en una plaza pública como en antiguo, sino en los televisores y en los cines de cualquier país o región.

Cabe destacar que la primera aparición del Joker fue en un cómic durante los años 40 del siglo XX. La relación del Príncipe del Crimen, cuya principal característica es su amplia sonrisa, con lo marginal es evidente. La risa aparece en el cómic, lo que fue excluido en la Antigüedad se une a lo que es rechazado en la actualidad. 
Bajtín (2003) también expone que uno de los elementos indispensables de la fiesta popular era el disfraz, o sea la renovación de las ropas y la personalidad social; claramente el Joker es un payaso, una satirización del ser humano.

Otro elemento importante en la lectura que hace Bajtín sobre la Edad Media y el Renacimiento, es la permutación de las jerarquías: se proclamaba rey al bufón, durante la fiesta de los locos se elegía a un abad, a un obispo o a un arzobispo de la risa, y en las iglesias sometidas a la autoridad directa del papa, se elegía un papa de la risa, se ponían las ropas al revés y los calcetines en la cabeza. Se invertía el orden de lo alto y lo bajo, se arrojaba lo elevado, lo antiguo, lo perfecto y lo terminado al infierno de lo interior material y corporal; este orden moría y volvía a renacer. El tiempo jugaba y reía.

Se debe puntualizar que el color del traje del Joker es morado, mismo color que utiliza el papa en su vestimenta durante la Cuaresma. El Príncipe del Crimen es un heredero de esta tradición medieval y renacentista, de acuerdo con los cómics analizados.

En los textos y el filme estudiados, el Joker es ese payaso, ese bufón que pone de cabeza a la sociedad y a los que viven en ella bajo sus cánones. Al respecto se señala en The Killing Joke (1988):

¡Señoras y señores! ¡Lo habéis leído en los periódicos! ¡Ahora temblad mientras contempláis al más raro y trágico de los errores de la naturaleza! ¡Os presento al... Americano medio! Físicamente ordinario, tiene un deformado sistema de valores. Notad el engreído sentido de la importancia de la humanidad, su desfigurada conciencia social y su envanecido optimismo. ¿No es para vomitar? Lo más repulsivo de todo son sus frágiles e inútiles nociones del orden y la cordura. Si se presiona demasiado... Se quiebran. ¿Cómo vive? Os preguntareis ¿Cómo puede este pobre y patético espécimen sobrevivir en este mundo irracional? La triste respuesta es "No muy bien”. ¡Enfrentado al inevitable hecho que la existencia humana es una locura, sin rumbo ni sentido, uno de cada ocho se vuelve un demente! ¿Quién puede culparles? ¡En un mundo psicótico como este... Cualquier otra cosa, sería una locura! (Moore, 1988, p. 34)

El ser humano es expuesto, es más que ridiculizado, es llevado a un absurdo del que no tiene salida, su lógica y sus valores son cuestionados, son puestos en la palestra con el fin de renovarse, mueren para renacer. Ello es claro en la eterna rivalidad de Batman con el Joker; la existencia de uno justifica la existencia del otro.

La crítica que se realiza se centra en una falta de perspectiva, señala que las cosas se pueden hacer de diferentes formas, tal y como se lo indica el Joker a Harvey Dent cuando lo visita en el hospital al final del filme:

Joker: Son los planificadores los que te tienen aquí. Tú eras un planificador. Tenías planes. Mira a donde te llevaron. Yo solamente hice lo mejor que sé hacer, tomé el plan que tenían y lo volví contra ustedes. Mira lo que hice con la ciudad con un par de barriles de gas y un poco de balas. Nadie entra en pánico cuando las personas seleccionadas son asesinadas. Nadie se asusta cuando las cosas son de acuerdo a un plan, incluso 
si el plan es terrorífico. Sí digo a la prensa que mañana morirá un mafioso, o que un camión con soldados será estallado, nadie entra en pánico. Porque todo es parte del plan. Pero cuando digo que un pequeño funcionario morirá, ¡Todos se vuelven locos! Introduce un poco de anarquía, desestabiliza el orden establecido y todo se vuelve caos. Soy un agente del caos. ¿Y sabes algo del caos? Es justo. (Nolan, 2009)

En ese caos, todo aparentemente, se encuentra en latencia y las posibilidades de todos son iguales.

Esta lectura demostraría la falta de visión que tiene la sociedad de integrar el todo, de que no debe cerrar posibilidades, de que debe busca abrir surcos en la tierra y en la vida, para burlar su mayor terror: la muerte. Por esto, el Joker asesina o deja vivas a las personas, porque él es el juego de la vida, hace maromas con las fuerzas de la creación y la destrucción: Eros y Tanatos. Igual ocurre con Menipo, en el Diálogo de los Muertos, que Bajtín (2003) refiere: en ese personaje se establece la relación que hay entre la risa y el infierno (la muerte), y la libertad del espíritu y la palabra.

El Joker está en esa frontera como se lee en el Arkham Asylum (1989): un día es un payaso y al siguiente es un asesino. En igual sentido ocurre al comienzo de la película, en el robo al banco, donde deja vivo al gerente, pese a ponerle una granada en su boca que al final no explota. Al Príncipe del Crimen no le interesa si mata o no, si lo atrapan o sigue libre, su misión no es ganar en el plano físico, sino desenmascarar toda la estructura establecida, como se revela en The Killing Joke (1988):
... me da igual que me atrapes y me envíes de nuevo al manicomio...Gordon se ha vuelto loco, he demostrado lo que quería. ¡He demostrado que no hay ninguna diferencia entre los demás y yo! Solo hace falta tener un mal día para que el hombre más cuerdo que existe enloquezca (Moore, La Broma Asesina)

El Joker es el bufón que se burla del rey, es como aquel niño que le dice al rey que está desnudo cuando los demás le mienten, juega con la dicotomía de lo bueno y lo malo. Se sabe el Rey del Mundo, mas no le interesa serlo; por ello le dice a Harvey Dent durante el filme que introduzca la anarquía; su poder está en ser dueño de todo y todos, y de nada y de nadie, como el Arconte número veintidós de las cartas del Tarot que puede ser el más alto y el más bajo.

De acuerdo con Bajtín (2003), a partir de Rabelais, la palabra y la máscara del bufón medieval que parodiaban los decires y ademanes de los saltimbanquis de feria, se asociaron al saber humanista, a la ciencia, a la práctica médica, a la experiencia política y a los conocimientos que poseía una persona que, por su posición y función en las cortes reales, conocía íntimamente los problemas y secretos de la alta política internacional de su tiempo. El Joker conoce todo su medio, pero no posee ese carácter oficial dentro del esquema de la sociedad; por eso es siempre el errante. En su figura se encuentran los embriones de la alegría y de la risa, disimulados en la liturgia en la época antigua.

Otro elemento relevante para este análisis es la relación del Joker con la fiesta de los locos, ritual cómico que existía en la Edad Media y el Renacimiento que discurría en 
forma paralela con los actos de la Iglesia. Según Bajtín (2003), este ritual se manifestaba con fuerza y perseverancia, donde la inversión paródica del culto oficial era acompañada por disfraces, mascaradas y danzas obscenas.

Casi todos los rituales de las fiestas de los locos eran degradaciones de los diferentes ritos y símbolos religiosos transferidos al plano material y corporal, que se destacan por su carácter de diversión: "Estos festejos son indispensables para que lo ridículo (bufonerías), que es nuestra segunda naturaleza, innata al hombre, pueda manifestarse libremente al menos una vez al año..." (Bajtín, 2003, p. 61).

Este carnaval o la fiesta de los locos tenía como misión servir de válvula de escape para esa "segunda naturaleza humana", como le llamaban a la risa. Esto se puede notar en el Arkham Asylum (1989) en una frase que emplea el Joker cuando Batman ingresa al asilo: “Joker: ¡Dejemos que el Festival de los Tontos comience!" (Morrison. 1989).

La alusión a la degradación de los símbolos religiosos es patente en este texto, cuando Batman se compara a sí mismo con Jesús y con Atis por la situación que vive dentro del psiquiátrico: "Soy como Atis al cedro y Cristo al madero" (Morrison, 1989).

Así mismo, en las páginas finales del Arkham Asylum (1989), se encuentra una descripción del Joker que evoca el cambio de estación:
Joker:

¿Quién es este loco inocente?

Así, en las sagas antiguas,

Leyendas míticas de bardos y druidas,

No había una reina igual a la primavera.

Donde el agua es aire

Y toda complejidad es resuelta.

¡Sí, Llena las iglesias con pensamientos obscenos!

Sé honesto a la Casa Blanca,

Escribe palabras indecentes ¡En las frentes de los niños!

Quema tus tarjetas de crédito

¡Usa tacones altos!

¡Las puertas del asilo están abiertas!

¡Llena los suburbios de asesinatos y violaciones!

¡LOCURA DIVINA!

¿Que haya éxtasis, éxtasis en las calles! ¡RÍE, Y EL MUNDO REIRÁ CONTIGO! (Morrison, 1989)

En este texto se palpa la subversión, lo complejo se hace sencillo, el agua es aire, se realiza todo lo socialmente indebido y se observa la relación esencial de la risa festiva con el tiempo y la sucesión de las estaciones.

Sin embargo, lo más importante es que hace una alusión directa a lo que ocurría en la Edad Media y el Renacimiento cuando se lee: “¡Sí, Llena las iglesias con pensamientos obscenos!", indicio que da la conexión perfecta con lo que ocurría en las fiestas de los locos. Así, la semiótica cultural hace su aparición para confirmar que el Joker es heredero del legado rabelesco. 


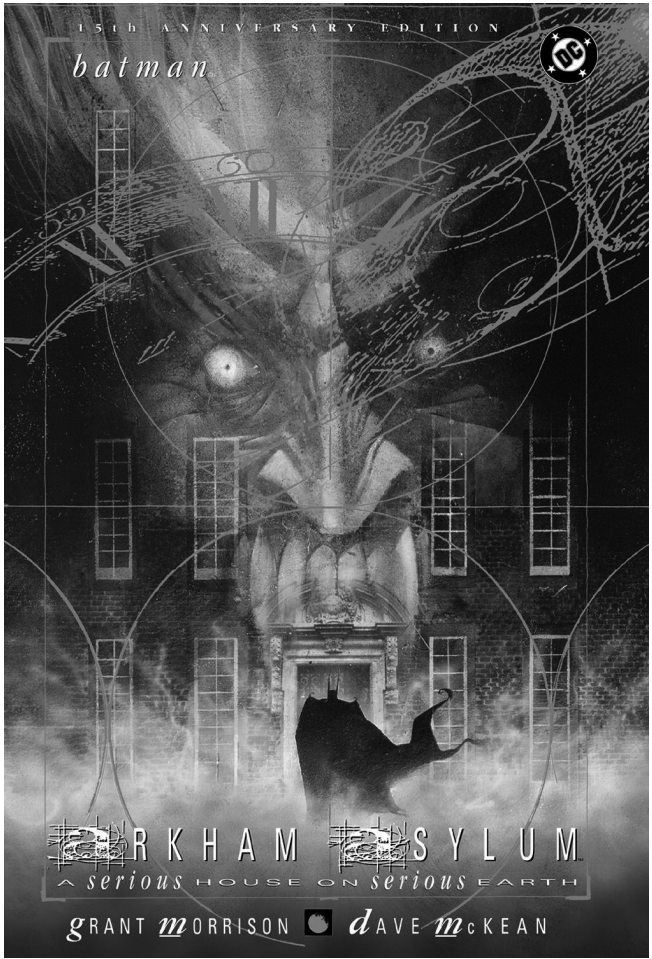

Imagen 3. Batman: Arkham Asylum. A serious house on a serious Earth

Fuente: https://www.google.com/search?biw=13 $66 \& b i h=654 \&$ tbs $=i s z \% 3 \mathrm{Al} \& \mathrm{tbm}=\mathrm{isch} \& \operatorname{sxsrf}=\mathrm{A}$ CYBGNR82EVJH1GG6qw8hRqmudVBGQ0fa $\mathrm{Q} \% 3 \mathrm{~A} 1569183428713 \& \mathrm{sa}=1 \& \mathrm{ei}=\mathrm{xNaHXbSCK}$ 87j_AbLt4jwAg\&q=arkham + asylum $+\mathrm{a}+$ serious + house + on + serious + earth\&oq $=$ arkham + asylum + a\&gs $1=$ img.3.0.013j0i3017.4747.5220..6957...0. $0 . .0 .180 .357 .0 \mathrm{j} 2 \ldots \ldots . . . .1 .$. gws-wiz-img.......0i67. oEQ-3apV81Y\#imgrc=T930u3a-7Z0hRM:

\section{Nociones de verdad}

- Se aprecia que los problemas que existen en Ciudad Gótica son resueltos por unos pocos y no por la amplia mayoría de los ciudadanos, a quienes les afecta todo lo que ocurre. En el caso de los cómics y el filme, son el hombre murciélago y el Príncipe del Crimen los que se debaten por el alma de la ciudad. Si se transfiere esta metáfora al plano de lo cotidiano, se rebela el problema que tiene la sociedad actual: nadie asume responsabilidades, se cree que es suficiente con elegir políticos que deben resolverlo todo, y eso convierte a la sociedad en la causante y en la perjudicada de sus propios males.

- Las figuras de Batman y el Joker no nacen casualmente, son hijas de un tiempo donde los discursos autoritarios son muchas veces disfrazados con el nombre de Democracia. Tanto los textos como el filme reflejan las tonalidades del gris inherentes a estas figuras, donde uno apela al orden $\mathrm{y}$ el otro dice las verdades. No todo es blanco o negro, bueno o malo.

- Batman es solo un personaje que cree estar haciendo el bien, que nunca pudo superar la culpa de algo sobre lo que no tenía control: el asesinato de sus padres; esto lo lleva a intentar salvar al mundo sin importar si rompe la ética imperante.

- Lo carnavalesco, la subversión y el contradiscurso se hacen presentes, hay un heredero de la risa que se presenta de manera baja y material, como ocurría con los bufones que recorrían de lado a lado los rincones de las ciudades durante la Edad Media y el Renacimiento.

- El caos y el azar surgen como las fuerzas regidoras de un mundo que apela al orden como modelo de salvación, pero que se encuentra a merced 
de las primeras. El Joker es el generador de esta nueva perspectiva de la existencia, por su contradiscurso y por su ambigüedad al no querer tomar el poder; da la impresión de estar en todos los niveles de la sociedad, como el caos mismo que se encuentra en todas partes.

- El Príncipe va más allá de la pantalla de un cine o de las hojas de una revista, intenta decir la verdad o nociones de ella, busca que se dude, es todo lo que Derrida (2003) plantea: buscar un punto intermedio que permita generar más de una interpretación. Todo es importante en el discurso de este personaje, la risa es tan universal como lo serio, es el aspecto festivo del mundo. El Joker parece ser la actitud deconstruccionista y la reivindicación de una tradición que es tan vieja como la humanidad misma, porque nace en el único lugar en que se le puede amar y detestar al mismo tiempo: dentro del ser humano mismo.

\section{Más allá de Derrida}

Se puede considerar esta perspectiva derridiana como algo válido, y que sin duda enriquece la lectura de los cómics y el filme en cuestión; mas se debe tomar en cuenta que se analiza una película que es parte de una trilogía donde el caballero oscuro, pese a sus dilemas, logra salvar a Ciudad Gótica de su mayor catástrofe. No hay mención alguna del desarrollo del héroe ni en la primera ni en la tercera películas. Igualmente, los cómics estudiados son parte de una veintena que fueron la fuente de inspiración de la trilogía de Nolan. Se dejan de lado, por ejemplo, cómics de la talla del Joker (2008) de Brian Azarello y The Dark Knight Returns (1986) de Frank Miller. Se está, sin ninguna duda, ante una lectura sesgada.

Se plantea que no existe un héroe en los términos que indica Bauzá (1998), ya que se supone que Batman no actúa de acuerdo con la ética que se refleja en la película. Sin embargo, se puede mencionar que el héroe nunca quiebra su única regla: no matar. Su honor está contenido en ella, su heroicidad consiste en no traspasar la línea que lo convertiría en un asesino. De acuerdo con Derrida (2008) el concepto de héroe cambiaría según a la época y la sociedad que lo determinan, mas Batman nunca asesina a nadie durante la trilogía de Nolan. Este carácter ético que poseen los héroes y que se mantiene a lo largo de la historia según Bauzá (2008), se revaloriza porque, aunque la forma de actuar de Batman es cuestionada por la gente que lo rodea y por la sociedad de Gótica, su regla permanece inquebrantable.

Se debe recordar que Batman actúa fuera de la ley, es ajeno a los límites sociales, por lo que su ética es distinta a lo que plantea la sociedad, y en este juego es donde aparece la ambigüedad y se duda del hombre murciélago. El héroe se define por sus actos y no por sus sombras, pero ambos elementos permiten que el personaje resuene en el nivel humano.

Sostiene el personaje de Johnny Lawrence en la reciente serie de YouTube Cobra Kai (2018-2019), que a él no le habían enseñado la diferencia entre la piedad y el honor y que por ello había pagado el precio. El 
hombre murciélago sí conoce esta diferencia, y entiende que debe llegar hasta cierto punto para lograr su cometido. Su archirrival se lo reconoce al final de The Dark Knight (2008): "tú no me matas por algún sentido de moral fuera de lugar...". Su moral, su código, su honor, no son una mala broma... Héroes allá donde los haya...

\section{Referencias}

Bauzá, H. F. (1998). El mito del Héroe. Morfología y Semántica de la figura heroica. Buenos Aires: Fondo de Cultura Económica de Argentina.

Bajtín, M. (2003). La Cultura Popular en la Edad Media y el Renacimiento: El Contexto de François Rabelais. Madrid: Alianza Editorial. España.

Derrida, J. (2008). De la Gramatología. Madrid: Siglo XXI Editores.

Moore A. y Bolland, B. (1988). The Killing Joke. New York: DC Comics.

Morrison, G. (1989). Arkham Asylum. A serious house on a serious Earth. New York: DC Comics.

\section{Filmografía}

Thompson, E. (Productora) Nolan, C. (Director). (2009). The Dark Knight. Estados Unidos: Warner Bros. Pictures.

\section{Sitios Web:}

Batworld (16 de octubre, 2009). Batman: La Broma Asesina. [Entrada de blog] Recuperado de: http://batworld.blogspot.com/2009/10/analisisde-batman-la-broma-asesina.html

Un tebeo con otro nombre (10 de abril, 2008). El final de la Broma Asesina [Entrada de blog] Recuperado de http://www.untebeoconotronombre. com/archive/2008/el_final_de_la_broma_asesina.html

Trazos en el bloc (20 de mayo, 2009). Crítica: Batman: La Broma Asesina de Alan Moore \& Brian Bolland. [Entrada de blog] Recuperado de http:// trazosenelbloc.blogspot.com/2009/05/ critica-batman-la-broma-asesina-dealan.html

Río Negro. Online (25 de enero, 2009). La humana locura de El Guasón. [Entrada de blog] Recuperado de http://www1 .rionegro.com.ar/diario/2009/01/25/123285603250.php

Pie de página cómics (diciembre 2006). Arkham Asylum [Entrada de blog] Recuperado de http://www.piedepagina.com/comics/html/arkham.htm 
